\title{
Characterization of the recognition of blood group B trisaccharide derivatives by the lectin from Marasmius oreades using frontal affinity chromatography-mass spectrometry
}

\author{
Brian P. Rempel ${ }^{1}$, Harry C. Winter ${ }^{2}$, Irwin J. Goldstein ${ }^{2}$ and Ole Hindsgaul ${ }^{1 *}$ \\ ${ }^{1}$ Department of Chemistry, University of Alberta, Edmonton, Alberta T6G 2G2, ${ }^{2}$ Department of Biological Chemistry, University of \\ Michigan Medical School, Ann Arbor, MI 48109-0606, USA
}

\begin{abstract}
A novel lectin from the mushroom Marasmius oreades (MOA) has been shown to bind to human blood group B oligosaccharides [1]. In the present work we examine the binding of a series of analogues of the blood group B-trisaccharide, $\alpha \mathrm{Gal}(1-3)[\alpha \mathrm{Fuc}(1-2)] \beta \mathrm{Gal}-\mathrm{OR}\left(1, \mathrm{R}=\left(\mathrm{CH}_{2}\right)_{8} \mathrm{COOMe}\right)$. MOA was biotinylated and immobilized on a micro column $(9.8 \mu \mathrm{L})$ for evaluation by Frontal Affinity Chromatography-Mass Spectrometry (FAC-MS) [2]. The trisaccharide 1 was found to be the epitope needed for maximum recognition $\left(K_{d}=3.6 \mu \mathrm{M}\right)$. A series of synthetic deoxygenated and O-methylated analogues of the B-trisaccharide $(R=O M e)$ were then screened against the lectin, and the key structural elements for binding were determined. OH- 4 of the $\beta$-Gal residue and $\mathrm{OH}-2$ of the $\alpha$-Gal residue were found to be critical for recognition. The FAC-MS technique also proved powerful in evaluating mixtures of compounds. Since the solution NMR structure and crystal structure of the B-trisaccharide are known [3], we propose the specific surface of the trisaccharide that is recognized by the lectin. Published in 2003.
\end{abstract}

Keywords: binding specificity, dissociation constant, frontal affinity chromatography coupled to electrospray mass spectrometry, lectin, blood group B trisaccharide derivatives, binding surface, carbohydrate-protein recognition

\section{Introduction}

Lectins are proteins or glycoproteins which have the rather remarkable property of binding carbohydrates in a very specific manner. Some lectins recognize sequences of two or more saccharides with specificity toward both inter-residue glycosidic linkages and anomeric configuration. For these reasons, lectins have proved to be useful reagents for the identification, isolation and characterization of the carbohydrate residues of glycoconjugates [4].

Frontal affinity chromatography coupled to online electrospray mass spectrometry (FAC-MS) is a method that has previously been applied to characterize lectin-carbohydrate interactions [5]. FAC-MS allows for the rapid screening of mixtures of compounds, and can be used to estimate the dissociation constant $\left(K_{d}\right)$ for protein-ligand interactions for each individual compound present in a mixture [2,6].

Winter et al. recently reported a novel lectin from the Marasmius oreades mushroom (MOA) and determined its bind-

*Author to whom correspondence should be addressed. ing specificity by agglutination studies and in solution by isothermal titration calorimetry [1]. The lectin was found to be specific to the carbohydrate portion of the human blood group B antigen. In the present work, we immobilized the MOA and by screening a series of structural analogues using FAC-MS, further characterized the binding specificity of the lectin.

\section{Materials and methods}

The MOA was biotinylated according to the procedure of Mo et al. [7]. The synthetic carbohydrates used (Figures 1 and 2) were available from previous work [8-10]. PEEK (polyetheretherketone) tubing, union and tee were from Fischer Scientific Ltd. and were used in all components of the chromatography. The column was prepared by packing controlled pore glass beads with streptavidin covalently attached (CPG-SA 37-74 $\mu \mathrm{m}$, CPG Inc., USA) into a $5 \mathrm{~cm}$ length of PEEK tubing (column ID $=0.50 \mathrm{~mm}$ ), blocked at both ends by a stainless steel frit (10 $\mu \mathrm{m}$ screen, Valco Instruments Co. Inc.), to form 

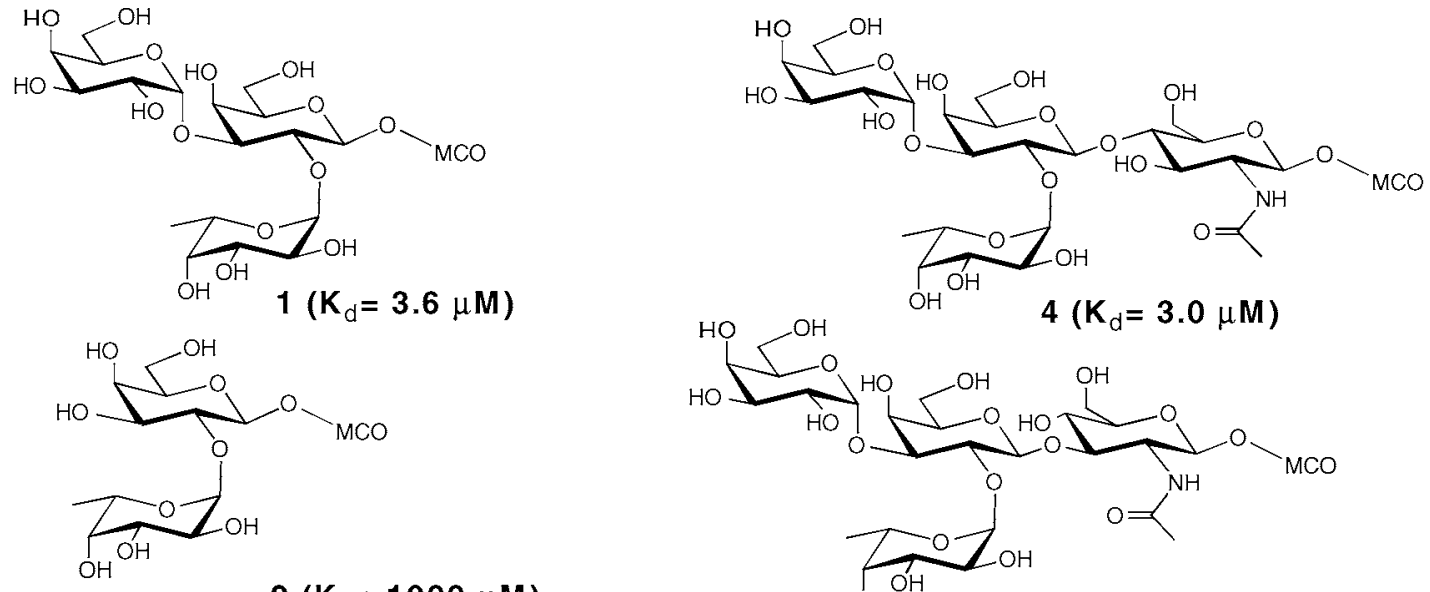

$2\left(K_{d}>1000 \mu M\right)$
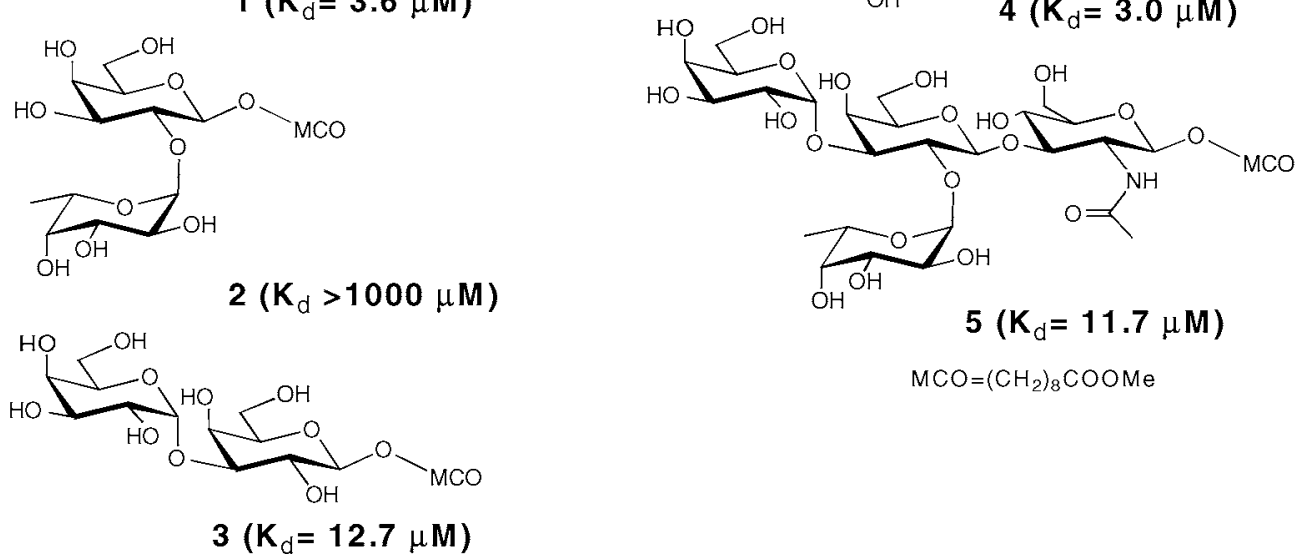

$\mathrm{MCO}=\left(\mathrm{CH}_{2}\right)_{8} \mathrm{COOMe}$

$3\left(\mathrm{~K}_{\mathrm{d}}=12.7 \mu \mathrm{M}\right)$

Figure 1. Structures and $K_{d}$ values of the oligosaccharides used to determine the minimum binding domain for MOA.
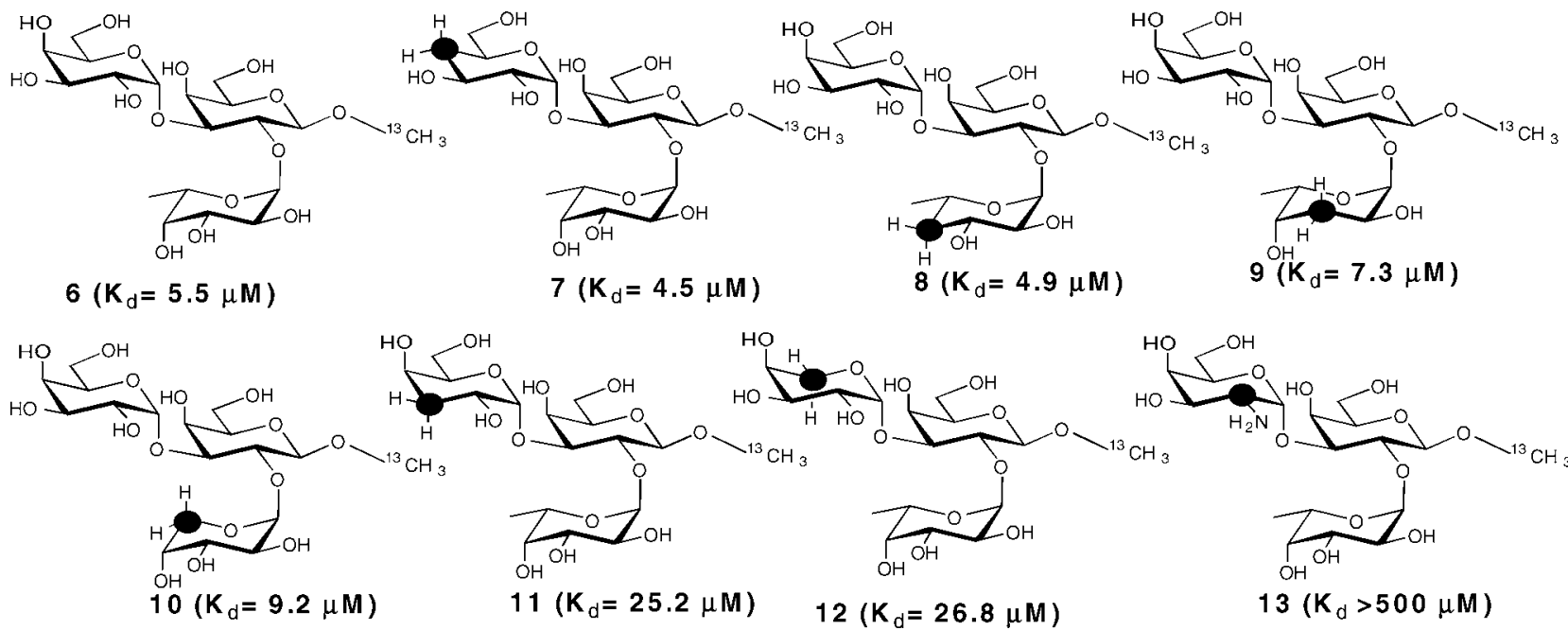

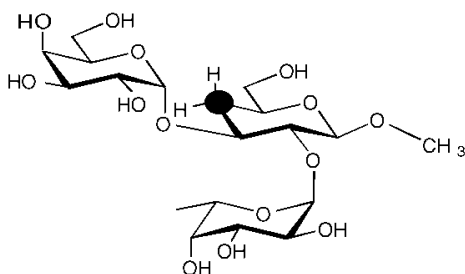

$14\left(K_{d}>1000 \mu M\right)$

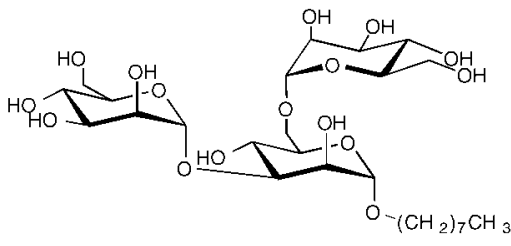

$15\left(K_{d}>1000 \mu \mathrm{M}\right)$

Figure 2. Structures and $K_{d}$ values of the oligosaccharide analogues used to map the binding domain of MOA. Structural differences from 6 have been highlighted.

a column with an internal volume of $9.8 \mu \mathrm{L}$. The biotinylated protein was loaded by injection at $8 \mu \mathrm{L} / \mathrm{min}$ of a protein solution $(0.1 \mathrm{mg} / \mathrm{mL}$ in phosphate buffered saline) until the column was saturated. Remaining streptavidin binding sites were then blocked by subsequent injection of d-biotin $(0.2 \mathrm{mg} / \mathrm{mL}, 1 \mathrm{~mL}$ in PBS buffer at $8 \mu \mathrm{L} / \mathrm{min}$ ). The column was subsequently equilibrated with ammonium acetate buffer $(10 \mathrm{mM}, 1 \mathrm{mM} \mathrm{NaCl}$, $\mathrm{pH}$ 7.2) and stored at $4^{\circ} \mathrm{C}$. 
Solutions were injected continuously using a multi-syringe pump (PHD 2000, Harvard Apparatus) into a flow selection valve (Rheodyne, model 9725) then into the MOA column. The post column eluent was mixed with an equal amount of HPLC Grade acetonitrile then sprayed into the sample inlet of a Hewlett-Packard series 1100 MSD single quadrapole mass spectrometer.

Three syringes were mounted on the pump; these contained the analyte solutions in buffer $\left(10 \mathrm{mM} \mathrm{NH}_{4} \mathrm{OAc}, 1 \mathrm{mM} \mathrm{NaCl}\right.$, $\mathrm{pH}$ 7.2), pure buffer and acetonitrile, respectively. The contents of the three syringes were continuously injected at $8 \mu \mathrm{L} / \mathrm{min}$ into the flow selection valve. Only one of the buffer or analyte solutions was injected into the column, the other going to waste. After each run, the column was re-equilibrated by passing buffer through it with online monitoring until it was verified that the analyte had been removed from the column.

Solutions were characterized first by analysis by the mass spectrometer in scan mode from m/z 100 to 1500 in $1.5 \mathrm{~s}$ in positive ion mode. Once the target ions were detected as their sodium adducts, they were monitored online in selected ion monitoring (SIM) mode to improve sensitivity. The nebulizer was held at a constant voltage $(4000 \mathrm{~V})$ with $480 \mathrm{mbar}$ positive pressure from $\mathrm{N}_{2}$. $\mathrm{N}_{2}$ drying gas was flowed through at $4 \mathrm{~L} / \mathrm{min}$. All retention volumes were calculated by comparing the midpoint of the analyte elution curve to that of the void marker. All data was processed with Microsoft Excel, and figures are presented as IGOR files.

\section{Results and discussion}

Figure 3 shows the composite intensity of the $\mathrm{m} / \mathrm{z}$ signal vs. time chromatogram of two individual runs in which equimolar solutions of compounds 1-4 and 1-3 + $\mathbf{5}$ were run as mixtures with $\mathbf{1 5}$ as a void volume marker in each solution. It was necessary to run two mixtures because $\mathbf{4}$ and $\mathbf{5}$ share the same $\mathrm{m} / \mathrm{z}$ ratio. As $\mathbf{1}$ and $\mathbf{4}$ co-elute, it can be seen that the addition of further sugar units past the $\beta$-Gal residue offers

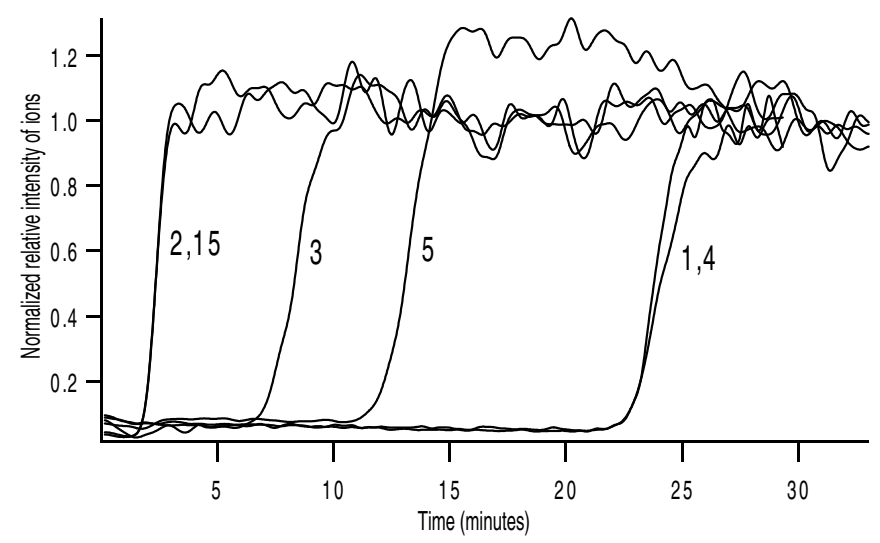

Figure 3. Composite FAC-MS chromatogram of two equimolar mixtures of 1-4 and 1-3 +5 run through the MOA column. no further increase in binding affinity. This indicates that the B-trisaccharide portion is sufficient for full recognition, in agreement with previously reported data [1]. Compound 5 shows a decreased affinity, as it elutes before 1. This suggests that there are some unfavorable interactions when changing the first inter-sugar glycosidic linkage from a $\beta$ (1-4) linkage to a $\beta$ (1-3) linkage. Since 2 had no binding detectable by our system, this indicates that the terminal $\alpha$-Gal residue is critical for recognition. The $K_{d}$ value for 3 , which lacks the $\alpha$-Fuc residue, is approximately 3.5 times larger than for $\mathbf{1}$. This indicates that the $\alpha$-Fuc residue contributed to the binding but that it is not essential.

The column capacity was determined by injecting solutions of varying concentrations of $\mathbf{1}$ and measuring the corresponding shift in retention volume. The relationship between concentration and retention volume is governed by Eq. (1), in which $K_{d}$ represents the dissociation constant, $V_{x}-V_{o}$ the difference between the void volume and the retention volume of the compound, $\left[X_{o}\right]$ the concentration of the analyte compound and $B_{t}$ represents the number of active protein binding sites on the column.

$$
V_{x}-V_{o}=\frac{B_{t}}{\left[X_{o}\right]+K_{d}}
$$

By plotting a graph of $\left(\left[X_{o}\right]^{-1}\right)\left(V-V_{o}\right)^{-1}$ vs. $\left[X_{o}\right]^{-1}$, the $K_{d}$ for a particular compound and the $B_{t}$ for the column can be determined from the slope divided by the intercept and the reciprocal of the intercept respectively [11].

Figure 4 shows the graph of Eq. (1) for the MOA column constructed using $\mathbf{1 5}$ as a void volume marker and $\mathbf{1}$ as a ligand. A dissociation constant of $5.2 \mu \mathrm{M}$ and a $B_{t}$ value of 1230 pmol were derived from the graph. This $K_{d}$ value agrees well with the dissociation constant of $3.6 \mu \mathrm{M}$ presented in Figure 1 as described below.

Figure 5 shows an intensity vs. time chromatogram in which compounds 1 and $\mathbf{6}$ were run competitively with $\mathbf{1 5}$ as a void volume marker. This figure clearly shows the increase in binding affinity that accompanies the addition of the hydrophobic MCO aglycone at the reducing end of the trisaccharide in $\mathbf{1}$. The signal from $\mathbf{6}$ is being "rolled up" (i.e. increases in intensity beyond that of the solution being injected before returning to the equilibrium intensity) by $\mathbf{1}$, which indicates competition for the same binding site on the protein with $\mathbf{1}$ having a greater affinity for the MOA [12]. We propose that this increased affinity may be attributed to the increased hydrophobicity of the MCO aglycone relative to a simple methyl group. This is likely due to direct interactions between a hydrophobic pocket on the protein and the lipidic aglycone.

Figure 6 shows the overlay of the intensity vs. time chromatograms for compounds $\mathbf{1 , 2}$, and 6-15 run individually and presented as a single figure. These compounds are analogues of 6, with varying substitutions or deoxygenations at different positions. Many of these compounds were available with a ${ }^{13} \mathrm{C}$ label in the O-methyl group for use in NMR studies. Each 


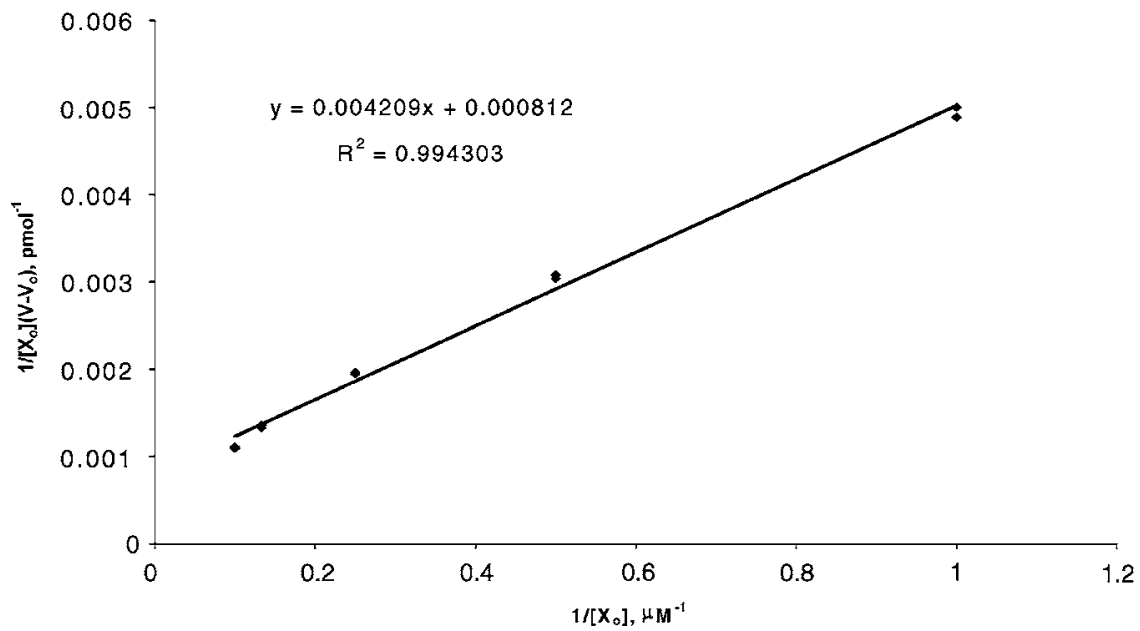

Figure 4. Determination of the column capacity and ligand binding affinity for 1 by FAC-MS.

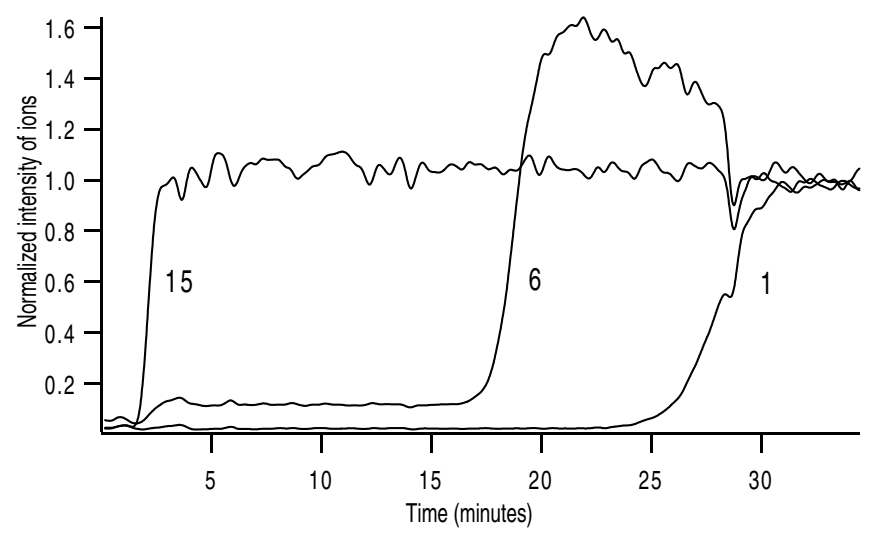

Figure 5. FAC-MS chromatogram of an equimolar solution of 6 and 1 flowed through the MOA column.

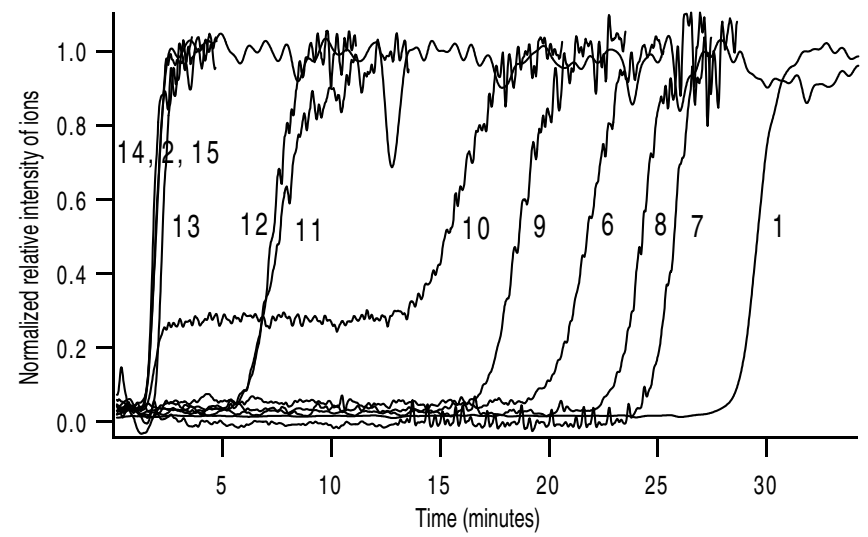

Figure 6. Overlaid chromatograms from individual FAC-MS runs using single $2 \mu \mathrm{M}$ solutions of 1,2 , and 6-15 flowed through the MOA column.

compound was run individually as a $2 \mu \mathrm{M}$ solution with $\mathbf{1 5}$ as the void volume marker. Solutions were run sequentially followed by online monitoring of the equilibration of the column with buffer to fully elute the compound. The elution profile for $\mathbf{1 5}$ is only displayed once, as it was invariant in all runs. Differences in individual retention volumes, compared to that of 15, yielded an estimate for the individual $K_{d}$ values using the $B_{t}$ value previously obtained. The value for $\mathbf{1}$ calculated in this manner, $3.6 \mu \mathrm{M}$, also agrees well with the graphically obtained value of $5.2 \mu \mathrm{M}$.

The analogues appeared to fall into three groups. The first group contained compounds that had very small change (relative to the parent 6) in affinity for the protein. This included compounds 7-10. The chromatogram for $\mathbf{1 0}$ demonstrated a biphasic shape, indicating a mixture of compounds at $\mathrm{m} / \mathrm{z}=512\left(\mathrm{M}+\mathrm{Na}^{+}\right)$. A $600 \mathrm{MHz}{ }^{1} \mathrm{H}-\mathrm{NMR}$ spectrum of this sample revealed that the terminal Gal residue was present as an $\alpha / \beta$ mixture (data not shown), with the desired $\alpha$ anomer as the major component. A compound in which the $\alpha$-Fuc residue was deoxygenated at the 2-position was unavailable.

In the second group, compounds $\mathbf{1 1}$ and $\mathbf{1 2}$ demonstrated a noticeable loss in affinity, indicating that substitutions at C-3 and $\mathrm{C}-5$ of the $\alpha$-Gal residues are detrimental to binding, but not critically. Finally, the structural changes in $\mathbf{1 3}$ and $\mathbf{1 4}$ resulted in compounds whose binding can barely (if at all) be detected using the present method, and which we correspondingly describe as inactive. It is known that the protein does not bind the blood group A trisaccharide (containing terminal GalNAc instead of Gal) [1]. Taken together, these results suggest that $\mathrm{OH}-4$ on the $\beta$-Gal and $\mathrm{OH}-2$ on the $\alpha$-Gal residues are critical for binding to the protein.

Figure 7 shows the intensity vs. time chromatogram of a single run in which an equimolar mixture of compounds 1 and 6-15 was injected in a single run. This creates a solution of twelve potential ligands in addition to the void volume marker 15, as $\mathbf{1 0}$ exists as a mixture of compounds as described above. The signal for $\mathbf{1 2}$ can be seen to "roll up," or increase in intensity beyond the intensity corresponding to the infusion concentration before leveling off again at this level. This phenomenon has been attributed [12] to 


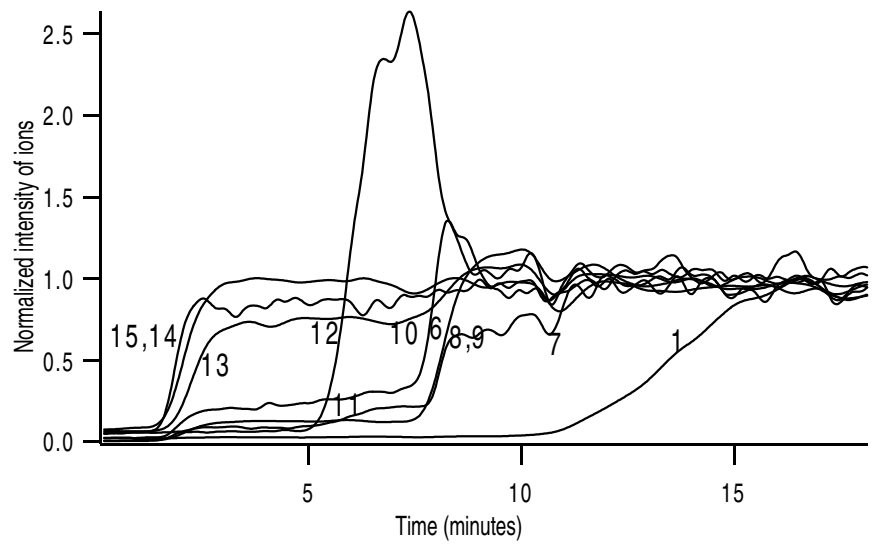

Figure 7. FAC-MS chromatogram obtained when a single, equimolar solution of $\mathbf{1 , 6 - 1 5}$ is flowed through the MOA column.

the compound being concentrated by the receptor-sites on the column, and then eluted as a more concentrated solution by a tighter binding ligand present in the mixture. Despite the presence of twelve ligands in solution, the FAC-MS system still retains the ability to discriminate between the compounds as the order of elution parallels their binding affinity as determined from the individual runs. This experiment is included to demonstrate the power of FAC-MS in dealing with mixtures.

Finally, the crystal and the solution phase conformation of the B-trisaccharide has been determined and is reproduced in Figure 8 [3]. We therefore propose the binding surface presented for recognition by the protein. $\mathrm{OH}-2$ on the $\alpha$ Gal residue and $\mathrm{OH}-4$ on the $\beta$ Gal residue are critical for recognition. The crystal structure of $\mathbf{6}$ shows these to be in close proximity in space (4.21 $\AA$ ), suggesting that they are forming so-called "key polar interactions" with the protein [13]. Changes made to the

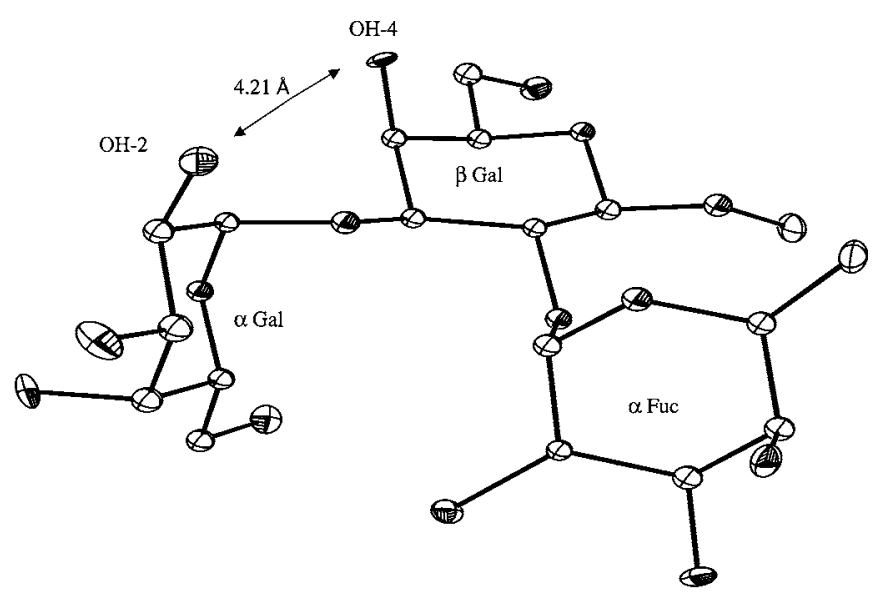

Figure 8. Crystal structure of the blood group B trisaccharide, with hydrogen atoms omitted for clarity. (From Otter et al.) Arrows point to essential $\mathrm{OH}$ groups in terminal and subterminal Gal residues. fucose residue did not result in any appreciable loss of affinity, suggesting that this sugar residue remains in contact with water. Other substitutions on the two galactose portions of the trisaccharide were tolerated with either a slight increase in binding affinity in the case of 7, or a decrease in binding affinity for $\mathbf{1 1}$ and 12. The approximately five-fold decrease in affinity for $\mathbf{1 1}$ and 12 suggests that $\mathrm{OH}-3$ and $\mathrm{OH}-6$ on the $\alpha$ Gal residue may be forming hydrogen bonds near the periphery of the binding site.

\section{Conclusions}

In this work, we examined the binding of a series of structural analogues of the blood group B trisaccharide, $\alpha$ Gal (1-3) $[\alpha$ Fuc(1-2)] $\beta$ Gal, to the lectin from the Marasmius oreades mushroom. OH- 2 on the $\alpha \mathrm{Gal}$ and $\mathrm{OH}-4$ on the $\beta$ Gal residues were found to be critical for binding. The protein appeared to be either completely or partially tolerant towards removal of other hydroxyl groups. From the permitted substitution patterns observed and the previously known crystal structure of the B-trisaccharide, we are able to propose a binding surface of the carbohydrate to the protein.

We further show the power of the FAC-MS technique by demonstrating the ability to discriminate among many compounds in a single run. A single injection of all of the structural analogues studied was able to resolve the compounds, which eluted in the order predicted by their individually determined dissociation constants.

\section{Acknowledgments}

The authors wish to thank the Natural Science and Engineering Research Council, Alberta Heritage Fund for Medical Research (to BPR) and NIH grant 29470 (to IJG) for financial support of this research.

\section{References}

1 Winter HC, Mostafapour K, Goldstein IJ, The mushroom Marasmius oreades lectin is a blood group type $\mathrm{B}$ agglutinin that recognizes the $\mathrm{Gal} \alpha 1,3 \mathrm{Gal}$ and $\mathrm{Gal} \alpha 1,3 \mathrm{Gal} \beta 1,4 \mathrm{GlcNAc}$ porcine xenotransplantation epitopes with high affinity, J Biol Chem 277(17), 14996-15001 (2002).

2 Schriemer DC, Bundle DR, Li L, Hindsgaul O, Micro-scale frontal affinity chromatography with mass spectrometric detection: A new method for the screening of compound libraries, Angewandte Chemie 37, 3384-7 (1999).

3 Otter A, Lemeiux RU, Ball RG, Venot AP, Hindsgaul O, Bundle DR, Crystal state and solution conformation of the B blood group trisaccharide $\alpha$-L Fuc $(1 \rightarrow 2)$ - $[\alpha$-D-Gal $p]-(1 \rightarrow 3)]-\beta$-D-Gal $p$ $\mathrm{OCH}_{3}$, Eur J Biochem 259, 295-303 (1999).

4 Goldstein IJ, Winter HC, Poretz RD, Plant lectins: Tools for the study of complex carbohydrates, In Glycoproteins II, edited by Montreuil J, Vliegenthart JFG, Schachter H (Elsevier, Amsterdam, 1997), pp. 403-74. 
5 Zhang B, Palcic MM, Mo M, Goldstein IJ, Hindsgaul O, Rapid determination of the binding affinity and specificity of the mushroom Polyporus squamosus lectin using frontal affinity chromatography coupled to electrospray mass spectrometry, Glycobiology 11(2), 141-7 (2001).

6 Zhang B, Palcic MM, Schriemer DC, Alvarez-Manilla G, Pierce M, Hindsgaul O, Frontal affinity chromatography coupled to mass spectrometry for screening mixtures of enzyme inhibitors, Analytical Biochemitry 299, 173-82 (2001).

$7 \mathrm{Mo} \mathrm{H}$, Winter HC, Golstein IJ, Purification and characterization of a Neu5Ac $\alpha 2-6 \mathrm{Gal} \beta 1-4 \mathrm{Glc} / \mathrm{GlcNAc}$-specific lectin from the fruiting body of the polypore mushroom Polyporus squamosus, J Biol Chem 275, 10623-9 (2000).

8 Lemieux RU, Venot AP, Spohr U, Bird P, Mandal G, Morishima N, Hindsgaul O, Bundle DR, Molecular recognition V. The binding of the B human blood group determinant by Hybridoma monoclonal antibodies, Can J Chem 63, 2664-8 (1985).

9 Nikrad PV, Beierbeck H, Lemieux RU, Molecular recognition X. A novel procedure for the detection of the intermolecular hydrogen bonds present in a protein-oligosaccharide complex, Can J Chem 70, 241-53 (1992).

10 Lemieux RU, The origin of specificity in the recognition of oligosaccharides by proteins, Chem Soc Rev 18(13), 347-741 (1989).

11 Kasai K, Oda Y, Nishikata M, Ishii S, Frontal affinity chromatography: Theory for its application to studies on specific interactions of biomolecules, J Chromatogr Biomed Appl 376, 33-47 (1986).

12 Chan NWC, Lewis DF, Schriemer DC, Hewko S, Hindsgaul O, Frontal affinity chromatography for the screening of mixtures, Combinatorial Chemistry and High Throughput Screening, in press.

13 Lemieux RU, Chemical mapping of protein carbohydrate complexes. Alfred Benzon Symp 36, 180-9 (1994).

Received 25 July 2002; revised 13 January 2003; accepted 24 January 2003 